\title{
Literatura como Instrumento de Internacionalização nas Relações Internacionais: Crônicas e Romance, Diálogos Intertextuais e o Construtivismo
}

Literature as an Instrument of Internationalization in International Relations: Chronicles and Novel, Intertextual Dialogues and Constructivism

Literatura como Instrumento de Internacionalización en las Relaciones

Internacionales: Crónicas y Romance, Diálogos Intertextuales y el

Constructivismo

Ricardo Japiassu ${ }^{1}$

\section{Resumo}

JAPIASSU, Ricardo. Literatura como Instrumento de Internacionalização nas Relações Internacionais: Crônicas e Romance, Diálogos Intertextuais e o Construtivismo. Rev. C\&Trópico, v. 43, n. 2, p. 147-161, 2019. DOI: https://doi.org/10.33148/Cetropicov43n2(2019)art.7

No momento em que o Departamento de Relações Internacionais da Faculdade Damas da Instrução Cristã pensa uma publicação que reflita acerca das defesas do Estado, remeto-me, imediatamente, à resistência cultural. Apresento, assim, um trabalho que reflete o pensamento da teoria construtivista, dialogando com a produção literária do século XIX. Pois, com olhar de embaixador, o negro abolicionista José do Patrocínio escreveu sobre a calamidade da seca que assolava os sertões nordestinos, onde, pelo menos, 500 mil pessoas pereceram. Utilizando-se das armas da feitura literária, ele defende um povo sofrido. A literatura torna-se, portanto, arma de resistência de uma população. Mais do que isso: sua defesa cultural. Este artigo discute a presença da teoria construtivista, dialogando com a produção folhetinesca publicada na corte.

Palavras-chave: Construtivismo. Literatura. Século XIX. Resistência Cultural.

PhD em Teoria Literária pela Universidade Federal de Pernambuco. E-mail: japiassu.ricardo@gmail.com Orcid: https://orcid.org/0000-0002-4553-3228 


\section{Abstract}

JAPIASSU, Ricardo. Literature as an Instrument of Internationalization in International Relations: Chronicles and Novel, Intertextual Dialogues and Constructivism. Rev. C\&Trópico, v. 43, n. 2, p. 147-161, 2019. DOI: https://doi.org/10.33148/Cetropicov43n2(2019)art.7

At the moment when International Relations Department of Damas Christian Instruction College think of a publication reflecting on State Defences, I refer, immediately, to cultural strength. Thus, I present a work reflecting the thoughts of constructivist theory, in dialogue with XIXth century literary production. Since, with an ambassador's gaze, the black abolitionist José do Patrocinio wrote on the drought calamity which ravage Brazilian northeast, where at least 500 thousand people perished. Using literature as a weapon, he defends a suffering people. Literature becomes, therefore, a weapon of resistance to a population. More than that, its cultural defence. This article discusses the presence of constructivist theory, in a dialogue with booklet production published in court.

Keywords: Constructivism. Literature. XIXth century. Cultural Resistance.

\section{Resumen}

JAPIASSU, Ricardo. Literatura como Instrumento de Internacionalización en las Relaciones Internacionales: Crónicas y Romance, Diálogos Intertextuales y el Constructivismo. Rev. CઐTrópico, v. 43, n. 2, p. 147-161, 2019. DOI: https://doi.org/10.33148/Cetropicov43n2(2019)art.7

En el momento en lo que el Departamento de Relaciones Internacionales de la Facultad Damas de la Instrucción Cristiana piensa una publicación que refleta acerca de las defesas del Estado, yo hago referencia, inmediatamente, à la resistencia cultural. Yo presento, por tanto, un trabajo que reflecte el pensamiento de la teoría constructivista, dialogando con la producción literaria del siglo XIX. Pues, con una mirada de embajador, el negro abolicionista José do Patrocinio escribió sobre la calamidad de la sequía que asolaba los desiertos nordestinos, donde al menos 500 mil personas perecieran. Utilizando-se de las armas de la literatura, ele defiende un pueblo sufrido. La literatura se torna, por tanto, arma de resistencia de una población. Más que eso: su defensa cultural. Este artículo discute la presencia de la teoría constructivista, dialogando con la producción folletinesca publicada en la corte.

Palabras clave: Constructivismo. Literatura. Siglo XIX. Resistencia Cultural.

\section{Introdução}

No momento em que as instituições de ensino indagam sobre a atuação da interdisciplinaridade junto ao fomento científico, questiona-se a respeito das conexões que se podem estabelecer entre as searas da obra de arte e as Relações Internacionais: além de embelezar, para que serve a literatura? Extinguir fronteiras, romper limites interpostos pelo tempo, desvendar o ainda estrangeiro - física ou psiquicamente, 
conhecer um mundo novo. O que pensar, pois, da cultura num país continental como o Brasil, como se dá a arte da escrita em regiões tão distintas? Lancei este questionamento no período de junho de 2011 a junho de 2012, quando realizei, junto ao curso de Relações Internacionais da Faculdade Damas da Instrução Cristã, a pesquisa científica Um Olhar de Embaixador: José do Patrocínio e o Nordeste Brasileiro. Na ocasião, recuperei dez crônicas de viagem publicadas em forma de folhetim pelo jornal carioca Gazeta de Notícias, no distante ano de 1878. Naquela época, a corte nada conhecia a respeito desta fatia do Segundo Império (PATROCÍNIO, 1973; SIMÕES, 2015).

Da mesma forma que os viajantes dos séculos anteriores, o periodista se espantava com o então desconhecido, observando, com o olhar perspicaz próprio aos embaixadores, perplexo, o que se passava nos estados nordestinos: a seca devastadora que consumia populações inteiras. Ele narra aos cariocas as belezas das paisagens, deslumbrado com um mundo tropical, selvagem e novo, embora muio sofrido. E ainda conversa com presidentes das províncias, realiza palestras abolicionistas nos teatros, visitava bispos e abarracamentos. Em suma, um embaixador. E o que faziam os moradores do Rio de Janeiro? Embebiam-se com textos reveladores do flagelo que acomete o semiárido brasileiro. Mas o que têm a ver as Relações Internacionais com um problema interno? Se o Brasil é continental, se José do Patrocínio viajava como embaixador, o que desvendava, então, a literatura folhetinesca? A face oculta da miséria de um mesmo povo. Tratava-se de uma nação dentro da outra, pois que as culturas definem os povos. Os nordestinos compreendiam um povo dentro de uma nação, cujas fronteiras eram demarcadas pela pena literária.

\section{O Construtivismo}

Como ponto de partida para as observações da teoria construtivista das Relações Internacionais, tomo as palavras de Jatobá (2013). De acordo com o seu ponto de vista, toda realidade é socialmente construída, o que, por sua vez, resulta das escolhas dos seres humanos, feitas por livre-arbítrio. Mas o que pode a opção de agentes humanos diante da calamidade de uma estiagem que afetou todo o hemisfério Sul do planeta? Especificamente no caso do Nordeste brasileiro, a população emigrou em massa dos sertões para a capital, impondo à história uma nova história a ser contada. O próprio Jatobá (2013) comenta: "Para todos eles, entretanto, a realidade resulta das ideias e práticas dos agentes sociais que constroem as estruturas nas quais vivemos, ao mesmo tempo em que somos por elas construídos". Podemos dizer, então, que, como agente da história, o próprio ser humano modela a sua existência. Assim, não existiriam Relações Internacionais sem a participação ativa do agente social, o ser humano, modelador dos fenômenos humanos e sociais.

Seria o construtivismo, portanto, um debruçar sobre a teoria social? A priori sim, pois que os construtivistas preferem enfatizar o olhar sobre agentes que lidam com as diversas estruturas sociais, cuja realidade - objeto da observação científica - é construída como resultado do modo como os agentes estruturam as relações sociais, por sua vez construindo os próprios agentes. Assim, as novas identidades impostas pelas vivências, 
as normas e regras do discurso e a cultura constituem as ferramentas básicas deste olhar específico das Relações Internacionais sobre o mundo em que estamos inseridos. Por conseguinte, tal teoria se centra nos fenômenos mentais e foca neles toda a sua atenção, sobretudo os coletivamente apontados e ressaltados por esta ciência, que se embebe dos significados produzidos pelos seres humanos. Mais do que isso: o papel da consciência humana na construção da realidade, os interesses e as respectivas identidades dos agentes sociais, o que é, de forma ressaltada, exógeno aos modelos racionalistas, mas componentes de qualquer realidade social, justamente em que estão embutidos da família à sociedade como um todo, são os agentes e a historicidade.

Acrescente-se que as expectativas dos atores convergem para um único ponto. Podemos dizer, então, que no caso do olhar de José do Patrocínio sobre os retirantes nordestinos, o único objetivo era que eles sobrevivessem à calamidade da seca, limitados a uma única liberdade de escolha, à institucionalização do clamor, que era bradar a fome, à miséria e à doença. Portanto, as ações sociais só adquirem significado porque se encontram em determinado contexto, por sua vez compartilhado por uma coletividade; nessa conjuntura, podemos assegurar que houve mais de 500 mil mortos. Não que se trata da reconstrução de parâmetros de ações, mas esperemos que seja medido por regras e normas, que não apenas conferem significado às ações, mas também moldam as decisões, dando, por sua vez, origem aos comportamentos sociais.

Mas por que obedecer às normas impostas em dado momento histórico? Se pensarmos no âmbito das secas, podemos dizer que as normas impostas recebem suporte dos agentes e decidem obedecê-las. Não se trata de mera obediência, mas de referências construídas em um dado momento histórico. Trata-se de obediência cega, imposta pelo Estado como mola de salvamento, obedecendo, por sua vez, a um discurso moral e jurídico. No caso particular do Nordeste brasileiro, o abolicionista, em suas crônicas de viagem, devassa a realidade, impondo novos paradigmas e conceitos, por sua vez manifestos em textos jornalísticos. Mas o que são os textos se não documentos atemporais? Daí ressaltar que a Literatura singra o tempo, fere as mentes e revela as particularidades de uma história atemporal, sendo a linguagem escrita uma arma de ação e não um mero recurso para descrever a realidade objetiva. Como afirma Jatobá (2013), "não é possível referir-se às ações humanas de modo absolutamente neutro". Mas o que desvenda a literatura?

\section{Os Textos Literários}

O objetivo deste artigo é também estabelecer as relações de intertextualidade que ocorrem internamente entre dois produtos literários da obra de José do Patrocínio (1853-1905), em relação à teoria construtivista das Relações Internacionais: as crônicas de viagem por ele intituladas Viagem ao Norte, dialogando com o romance de sua autoria, Os Retirantes, ambos iluminados pelo construtivismo. Em profunda interação com os meios de publicação comuns àquela segunda metade do século XIX, ou seja, os jornais da corte - gênero genuinamente brasileiro - as referidas crônicas foram inicialmente publicadas em forma de folhetim, nos rodapés da primeira página da folha 
carioca Gazeta de Notícias, no ano de 1878, no periódico junto ao qual atuava como jornalista. O romance Os Retirantes, por sua vez, foi publicado pela editora do mesmo jornal, após visita do escritor ao Nordeste brasileiro, sobretudo ao Ceará, onde ele mais presenciou a calamidade da seca de 1877-1879, no ano de 1879. Esta obra, ressalte-se, é apontada pelo historiador da literatura brasileira, Afrânio Coutinho, como sendo precursora, já neste momento de nossa história, do movimento regionalista, desenhado na literatura brasileira na primeira metade do século XX. Este projeto pretende, pois, investigar a relação do produto jornalístico dialogando com o construtivismo: isto é, as dez crônicas que compõem o livro Viagem ao Norte - Apontamentos de José do Patrocínio, e o romance de tese Os Retirantes, que, embora publicado em um único tomo (na primeira edição, sendo dois na segunda), apresenta características de romance folhetim, isto é, um folhetim de tese. Publicado no ano seguinte às crônicas, traz interfaces intertextuais da primeira obra. Assim, este conjunto abre novas perspectivas de conhecimento para a história da literatura nacional, revelando camadas pouco estudadas da nossa história ambientada nas secas nordestinas.

Do ponto de vista que mais nos interessa, ou seja, de uma nova abordagem das Relações Internacionais sobre as ciências literárias, podemos ter como parâmetro de partida o que nos diz o professor Thales Castro (2012), que ressalta o quanto a escola construtivista foi influenciada, sobretudo, pela sociologia, sendo, por conseguinte, composta por três fatores preponderantes: condições materiais, interesses e ideias. Vejamos o que ele diz:

O Construtivismo associa a forma de mútuas ações com o processo dinâmico envolvendo agentes e estrutura de maneira a construir o ethos das Relações Internacionais. Outras premissas são importantes a serem expostas: o pensamento, as ideias e os valores possuem força maior que as estruturas materiais disponíveis; as crenças intersubjetivas representam os meios (canais) por onde passam os fluxos de relacionamento internacional; e, por fim, a formação das ideias e dos ideais fazem parte da construção dos interesses, das identidades e da consciência partilhada dos agentes internacionais (CASTRO, 2012).

\section{Uma obra em perspectiva}

Esta pesquisa é um aprofundamento dos resultados obtidos quando da realização do meu Doutorado Direto, quando me pus em contato com o romance folhetim - entre outros de Raul Pompeia e Artur Azevedo - de autoria de José do Patrocínio: A Ponte do Catete - e o analisei. Até então inteiramente desconhecido no seu pendor literário, debrucei-me primeiro nas excelentes e aguerridas crônicas abolicionistas de sua autoria, bem como no também romance de tese Motta Coqueiro ou A Pena de Morte. Ressalte-se que toda a obra deste integrante da Academia Brasileira de Letras é permeada por recursos literários, sobretudo no que diz respeito à paródia, recorrente, aos 
macetes folhetinescos, quer seja o culto à peripécia, a digressão moral, a crise psíquica ou ainda a conclusão moral, recursos apresentados, quanto ao gênero, pelo teórico da literatura brasileira, Antônio Cândido.

Especificamente no que diz respeito ao gênero folhetinesco encontrado nesta obra, vai muito bem a caracterização da pesquisadora de folhetins, Meyer (2005): "desgraça pouca é bobagem". Ressalte-se que toda a fortuna crítica angariada ao longo do Doutorado Direto possibilita incursão de fôlego científico à empreitada de escrever este artigo.

\section{Interdisciplinaridade: o que oferece a Literatura às Relações Internacionais}

A segunda metade do século XIX, sobretudo na corte, naquele Segundo Império brasileiro, é marcada pela ebulição política e cultural. Muitos dos intelectuais compunham as trincheiras abolicionistas e republicanas. Este era justamente o caso de José do Patrocínio - filho de uma escrava com um padre - considerado pela história nacional como o maior líder abolicionista negro da capital do império. Inflamado, apresenta em seus romances sempre um olhar crítico sobre a condição social da grande massa formadora da população brasileira, a saber, os negros, cativos ou libertos. Até em Os Retirantes, que contempla outra face da população brasileira em seu bojo, ele representa na ficção, sempre, a condição de escravos, injustiçados, oprimidos e maltratados. Tudo isto em confronto com uma camada rala enquanto estrutura social e fina (enquanto estando no topo da pirâmide social do país) da nobreza brasileira. Especificamente no que se refere a Os Retirantes, o que marca a característica folhetinesca de fait-divers é, ao contrário dos romances anteriores, o debruçarse sobre a condição de desvalidos, sejam negros ou brancos, personagens livres ou presos à senzala. Descatamos que nesta estiagem que atingiu todo o sertão nordestino morreram mais de 500 mil almas. E porque um fait-divers? Justamente porque não se morre tanta gente de uma só vez numa mesma região. Inicialmente incrédulo, o escritor confessa em uma de suas crônicas de viagem, em tom de remorso: "Eu tenho pago bem caro a minha incredulidade!"(SIMÕES, 2015). É justamente neste tom que ele tece este romance de tese, desta vez contra os ditames da Igreja, quando acusa de vilezas o clero cearense; essa mesma ideia permeia tanto as crônicas quanto o folhetim.

Em se tratando de um folhetim de tese, encontramos a vileza do Padre Paula, da paróquia de B.V., fincada no sertão cearense, que seduz a jovem Eulália e depois se retira para Fortaleza, onde, mentindo, encontra apoio do arcebispo da capital. A desgraça da jovem seduzida é grande: ela abandona a casa e a família e, nos grotões cearenses, num incidente, aborta o filho, sendo protegida pelos cangaceiros do bando dos Viriatos, cujo chefe é Virgulino. Aqui, na obra de José do Patrocínio, há um prenúncio antecipando à presença do maior líder do cangaço nacional, Virgulino Ferreira, o Lampião, que devastou os sertões nordestinos, de influência cultural pernambucana, na primeira metade do século XX. Em Os Retirantes, encontramos: "O resto da quadrilha dos Viriatos salvou-se ganhando as alturas do Cariri, enquanto que o Diabrete, 
desligado dela pela morte do pai, veio juntar-se a Virgulino na vendola das vizinhanças de B.V., onde partiram em procura da família do segundo"(PATROCÍNIO, 1973). E acrescenta: “- Ah! A seca tem sido inverno para muita gente"(Op. Cit.).

Para salvar as irmãs e a tia, Eulália se prostitui em Fortaleza, onde consegue custear a retirada das flageladas para a Amazônia e sucumbe em meio às doenças sexualmente transmissíveis. Este olhar de terror está registrado nas duas formas de narrativas de José do Patrocínio, as crônicas e o romance. Especificamente na prosa mais longa, ele redige: “- Uma pouca vergonha: família em que há mulher bonita não sente faltas; a água aumenta logo pelos seus bonitos olhos"(PATROCÍNIO, 1973, Volume II - p. 92). Mais adiante, lemos: "Além disso, corria a fama de que a beleza das mulheres era o aferidor das necessidades das família, e os empregados, para provê-las, exigiam dos chefes que fossem as filhas, as esposas e as irmãs que as relatassem" (Volume II, p. 137). E a narrativa piora: "Estava-se em Arronches, que parecia ser o quartel-general da miséria; meninas que teriam, no máximo, 13 anos, tinham já estampados nos rostos e nos colos descarnados os estigmas da perdição. Grandes círculos dartrosos gravavam nos semblantes tristonhos daquelas infelizes a condenação eterna dos encarregados dos socorros!” (Volume II. p. 177). Em Viagem ao Norte - Apontamentos de José do Patrocínio, por sua vez, encontra-se, em Ruas e Praças da Fortaleza, publicado na terça-feira, 23 de julho de 1878: "Todas elas, filhas dos Sertões, santificadas por uma vida simples, sem sedutores, sem Dom Juans miseráveis, chegam às cidades, mumificadas, é certo, porém virgens. A libidinagem abastada pôs-se logo ao encalce das suas grinaldas e propôs-lhes o terrível dilema: rendei-vos ou contai com a morte. Mães, pais, maridos, os venerados atalaias da pureza da família, colocados em tão dura alternativa, e sem força para reagirem, cedem à transação ignóbil da honra pela vida” (2015, p. 50-51).

Neste momento, vale debruçar-se sobre o pensamento do teórico das Relações Internacionais, Gilberto Sarfati que, em Teoria das Relações Internacionais, pondera: "O Construtivismo, em contraste, se preocupa com a pergunta: de onde vêm os interesses dos Estados? Essa teoria acredita que a convivência social modifica os agentes, quer dizer, os Estados não podem ser considerados como verdades exógenas; eles são construções sociais desenvolvidas ao longo da história"(SARFATI, 2005).

$\mathrm{Na}$ conclusão do romance Os Retirantes, encontramos o seguinte trecho: "A cidade de ... recebe o seu novo vigário um digno apóstolo da religião do Calvário. Prouvera a Deus que sempre a nossa fé tivesse como órgãos homens iguais: a moralidade e a caridade reinariam eternamente sobre o mundo"(PATROCÍNIO, 1973, Volume II, p. 314). Esse tipo de romance, muito comum na literatura francesa do século XIX, tenta provar um argumento: na Igreja não encontramos correção; pelo contrário, uma leva de homens corruptos, um antro de desocupados, mentirosos, que não cumprem as determinações da própria instituição. Impulsivo, José do Patrocínio narra: “- Vocês souberam do que se passou hoje na hora da missa? - disse Paula a um grupo de retirantes que, de chapéu na mão, o escutava. Uma série de calúnias foi inventada contra mim, e insultaram-me como um assassino e sedutor" (PATROCÍNIO, 1973, Volume II, p. 226). E acrescenta: 
"O coro e um avarandado próximo, mobiliados de cadeiras cômodas e numeradas como num teatro, ostentavam à claridade crepuscular uma preocupação hierárquica no domínio da igualdade cristã. Sob elas jaziam, estendidos em cima de redes sórdidas, moribundos que a demasia da anasarca ou o emagrecimento devido ao relaxamento intestinal tornavam deformes.

$[\ldots]$

[...] perguntou-lhe quando poderia falar ao bispo.

- Sua Excelência tem estado incomodado e não recebe ninguém. $[\ldots]$

O sacerdote, que estava no confessionário, levantou-se por fim e, erguendo a voz, perguntou se não havia mais ninguém para confessar-se.

- Se está algum dormindo, acordem-no, porque, em saindo daqui, não estou mais para aturar maçada" (PATROCÍNIO, 1973, volume II, p. 226-227).

Quanto à condição dos negros cativos, José do Patrocínio narra, em Viagem ao Norte, mais precisamente na crônica Abarracamentos e Pegadorias dos Retirantes na Fortaleza, publicada pela Gazeta de Notícias, no sábado, 3 de agosto de 1878:

Quem tem viajado pelo interior das províncias experimentou de certo a dolorosa impressão causada pelo aspecto das senzalas dos escravos.

Parece que na sua construção houve o pensamento de escarnecer do trabalho e aviltar uma raça. Ao passo que o aspecto das mesquinhas moradas denuncia acomodações deficientes, as casas de vivenda dos senhores ostentam-se espaçosas à plena abundância de ar e de luz, esbanjada com pulmões que apenas têm de respirar em feliz ociosidade, com olhos que só têm de espairecer tédios venturosos(SIMÕES, 2015).

Em Os Retirantes, encontramos este outro trecho:

No quarto puseram-se os três a conversar. Monte referiu que os seus credores tinham sido inexoráveis; não quiseram estar por nenhuma espera. Nesse mesmo dia ia dar ordem para que os seus escravos fossem para o Aracati à disposição dos credores: pobres escravos, a quem ele tinha vergonha de dizer a sorte que os esperava. Mas não trazia ressentimento: o estado da província era tal que ninguém podia ter confiança no dia de amanhã 
$[\ldots]$

- É que ainda tenho de voltar ao Aracati; o preço dos escravos baixou muito, e eu quero ver se eles dão revés às minhas dívidas" (PATROCÍNIO, 1973, Volume I, p. 167).

Outro exemplo de intertextualidade se encontra na crônica No Ceará, publicada na mesma folha, no sábado, 20 de julho de 1878. Ela versa a respeito dos templos católicos:

Tem separações para três estados: clero, nobreza e povo. Ao clero pertence de direito a capela-mor, ao povo o corpo da igreja, à nobreza uma linha de varandas com cadeiras competentemente enumeradas.

Estas são pagas a bom preço durante as solenidades da Semana Santa, que são verdadeiras récitas em benefício.

[...]

Ainda no dia dezesseis de junho aglomerou-se em torno do patíbulo divino a religiosa multidão. Dizia-se que um grande milagre acabava de operar-se: o cruzeiro marejava água, anúncio sobrenatural da terminação da calamidade que flagela a província.

Ao passo que a pretensão do clero cearense abusa desaforadamente do bom senso das classes ilustradas e da credulidade pública, em nome do mesmo Deus e em nome da caridade, oito mulheres e uma pequena associação literária esforçam-se em concorrer eficazmente para minorar o padecimento do povo (SIMÕES, 2015).

Em Os Retirantes, encontramos:

O sacerdote lá estava empregado no seu mister de confessor, com o semblante carregado em sinal de uma austeridade de comédia e enfado pelo trabalho a que era obrigado.

Quando se desocupou e veio falar a Augusto Feitosa, começou logo por afetar uma urgência, que não passava de um assomo de grosseria.

- Viu o senhor em que tenho estado ocupado. Confessei vinte e tantos retirantes moribundos. Ora, eles sãos causam nojo, imagine o que serão nesse estado"(PATROCÍNIO, 1973, Volume II, p. 265). 
Neste ponto da análise científica, podemos tomar como parâmetro o que nos lega Gilberto Sarfati (2005, p. 261-262), que opina:

Desta forma, vemos que as identidades, tanto nossa como as dos Estados, são socialmente construídas, porque a relação com o outro é que forma a minha percepção sobre mim mesmo. Ou seja, são adquiridas pelo processo de relacionamento entre os Estados. Portanto, não poderíamos dizer que um Estado $\mathrm{X}$ tem um interesse conflitivo em relação ao Estado $\mathrm{Y}$ antes de os dois se relacionarem. A identidade é a base da construção dos interesses e somente passa a existir quando ambos começam a se relacionar.

E acrescenta, com lucidez e inteligência:

"Tendemos a nos aproximar daqueles que, de alguma forma, possuem características em comum com cada um de nós. Ao mesmo tempo, tendemos a nos afastar de pessoas cujas características pessoais tendem a se opor à forma como nos vemos (nossa identidade). Como você, a priori, poderia gostar de uma pessoa ou odiá-la antes de, ao menos, tomar contato com ela? Somente por puro preconceito haveria uma identidade negativa determinada a priori. De outra forma, apenas o contato social nos indicaria que tipo de relacionamento manteríamos com cada uma das pessoas que nos cercam" (p. 262).

As marcas da intertextualidade são visíveis até mesmo quando José do Patrocínio se refere à geografia e, consequentemente, à maneira como os flagelados se alimentam. Vejamos o que ele narra em Os Retirantes: "Ao lado do caminho viam-se já grandes montes de cascas secas de croata, orquídea venenosa, que entretanto serve de alimentação aos famintos"(PATROCÍNIO, 1973, Volume II, p. 43).

E nas crônicas de viagem:

Acendem uma fogueira em que assam as folhas do croata, única refeição que lhes resta, e é ansiosamente esperada pelas criancinhas, que, assentadas em torno da fogueira, coçam impacientes as cabecinhas encardidas pela poeira das jornadas.

Algumas famílias conduzem, atados por uma corda ao pescoço, magros cães que lhes devem servir de alimento em ocasião extrema (SIMÕES, 2015). 
Já num segundo momento de análise, José do Patrocínio faz, em Os Retirantes, a intertextualidade com o romance Vidas Secas, de Graciliano Ramos. Aqui, temos o cachorro Amigo, que será devorado pela família retirante de Eulália, enquanto, no segundo, encontramos a cadela Baleia, que também serve de repasto ao clã flagelado.

Uma marca daquele fazer literário da segunda metade do século XIX é justamente a divulgação de ideias através dos periódicos. Nesse sentido, Os Retirantes é menos conhecido que as demais obras do autor, já que é publicado não pelos jornais, mas em formato de livro, embora, ressalte-se, o texto seja marcado por macetes folhetinescos. Entretanto, as crônicas de viagem influenciaram os leitores da corte, pois que cinco textos deste gênero foram publicados ainda quando o jornalista se encontrava no Nordeste brasileiro, apontado pela geografia da época como Norte do Brasil. Recurso mais sofisticado à época, toda a redação foi remetida à Gazeta de Notícias via telex. "Pouco depois, é o cabo submarino que liberta a informação externa da subordinação dos paquetes, e o telégrafo une progressivamente as zonas mais próximas ao centro" (SODRÉ, 1977).

Retomemos o embarque da viagem na corte.

Segunda-Feira, 13 de maio de 1878. Primeira página da segunda coluna da Gazeta de Notícias.

Segue hoje para o Ceará, no vapor nacional Pará, o nosso companheiro de redação, José do Patrocínio.

Os [...] horrores por que tem passado ultimamente aquela infeliz província, os dramas de miséria que ali têm repetido, despertaram no nosso distinto colega os desejos de apreciar de perto tão horrível situação, e face com tais elementos em livro, que há de necessariamente comemorar tão triste acontecimento, e ser ao mesmo tempo mais uma do talento do festejado autor de Motta Coqueiro.

É louvável e pouco vulgar o espetáculo do jovem escritor, que se arrisca a tão incômoda viagem para escrever com verdadeiro conhecimento de causa.

A empresa da Gazeta de Notícias, a quem ele comunicou os seus desejos, resolveu comissioná-lo nessa província, resolução que trará uma dupla vantagem para os leitores desta folha: a de notícias exatas e minuciosas acerca do estado da população daquela parte do Império, e a publicação do livro de nosso companheiro, a quem desejamos feliz viagem. ${ }^{2}$

2 Este texto foi extraído diretamente do microfilme do periódico, realizado durante a pesquisa, em leitor de microfilme da Fundação Joaquim Nabuco. 
Há, porém, curiosidades a serem conhecidas: a Gazeta de Notícias, em 1878, tinha uma tiragem diária de 18 mil exemplares, isto para o Rio de Janeiro, com seus 300 mil habitantes, segundo o censo populacional de 1872 . Tinha a maior taxa de analfabetos do país: apenas seis mil leitores, ou seja, $2 \%$ da população. O historiador da imprensa brasileira, Nelson Werneck Sodré (1977), comenta: “O acontecimento jornalístico de 1874 será o aparecimento da Gazeta de Notícias, de Ferreira de Araújo, 'homem de iniciativas saneadoras, tendo reformado a imprensa em seu tempo, para dar espaço à literatura e às grandes preocupações, com desprezo pelas misérias e mesquinharias da polícia”'. Obedientes a este novo parâmetro, faço minhas as palavras do mestre Machado de Assis:

O folhetim nasceu do jornal, o folhetinista por consequência do jornalista. Esta íntima afinidade é que desenha as saliências fisionômicas na moderna criação. O folhetinista é a fusão admirável do útil ao fútil, o parto curioso e singular do sério, consorciado com o frívolo. Estes dois elementos, arredados como pólos, heterogêneos como água e fogo, casam-se perfeitamente na organização do novo animal (1985, p. 18).

Mas o que falar do gênero crônica, tão presente nesta segunda metade do século XIX? Segundo a classificação do pesquisador da literatura Luiz Beltrão, podemos classificar essas narrativas, especificamente, como sendo locais e urbanas, pois abordam aspectos específicos da vida na cidade de Fortaleza, onde José do Patrocínio se demorou mais amiúde, muito embora tenha visitado as capitais de Salvador, Maceió, Recife, João Pessoa (então Paraíba do Norte) e, por fim, a capital do Ceará. Ressalte-se a crônica Ruas e Praças da Fortaleza, publicada pela Gazeta de Notícias na terça-feira, 23 de julho de 1878. Seguindo esse mesmo raciocínio, encontramos tal gênero enquadrado como crônica sentimental, pois os textos apelam para a sensibilidade do leitor, quando os fatos influenciam a susceptibilidade do leitor. Veja-se, por exemplo, a crônica Ruas e Praças da Fortaleza:

A cada canto há um quadro horroroso que nos prende a atenção, uma lágrima a enxugar, uma indignação a conter.

Fui visitar os armazéns em que são empilhados os retirantes que devem ser transportados para outras províncias.

Saí com o coração transpassado pela contemplação de tanta miséria, e quando pensava ter concluído meu sacrifício matinal, ao dobrar o oitão do armazém, ouço o resmonear de uma voz, que partia de um grupo formado a poucos passos de mim (SIMÕES, 2015, p. 45). 
Em artigo redigido sobre José do Patrocínio, intitulado O Relato de José do Patrocínio no Nordeste Brasileiro e a Identificação de Elementos Característicos do Gênero Literário da Crônica, para a conclusão de pesquisa científica fomentada pela Faculdade Damas da Instrução Cristã, a então aluna Daylhane Cunha redigiu o que segue:

\begin{abstract}
Diante de tal perspectiva, é conferida à crônica a faculdade de informar por meio do subjetivo. Para isso, como Moisés (1979) pontua, sua estrutura é breve e narrada na primeira pessoa do singular, sendo responsável por - junto a fatores tais como linguagem fácil, marcas de oralidade e discurso em delongas -, criar uma conversa imaginária entre autor e leitor, ao qual o cronista manifesta sua opinião pessoal a respeito do que está sendo discutido.
\end{abstract}

E acrescenta: "Para Tuzino (2009), a leitura de mundo oferecida por aquele que produz uma crônica é exatamente ética, na medida em que deixa evidente (muitas vezes pelo próprio espaço destinado ao texto na diagramação do jornal, por exemplo) ao leitor de que aquele texto é autoral, é opinativo".

O também historiador da literatura brasileira, Afrânio Coutinho, caracteriza tal crônica narrativa como uma narrativa cujo eixo é uma história. O que, de fato, acontece, sobretudo nas crônicas mais aguerridas de caráter político: Administração Estelita e Administração Aguiar. Por fim, encontramos na Gazeta de Notícias:

Terça-Feira, 13 de agosto de 1878. Primeira página, oitava coluna da Gazeta de Notícias.

“Chegou ontem do Ceará o nosso companheiro de redação José do Patrocínio. Começaremos por estes dias a publicar os apontamentos que trouxe de sua viagem àquela província”.

\title{
6. Conclusão
}

Depois de percorrermos os caminhos trilhados por teorias literárias, bem como as visões científicas das Relações Internacionais, podemos fazer nossos os pontos de vista dos teóricos Nogueira e Messari (2005) na sua Teoria das Relações Internacionais. De acordo com o ponto de vista deles - com o qual concordo e me identifico - vivemos num mundo por nós construído, onde obviamente somos os protagonistas e agentes realizadores dos produtos por nós mesmos escolhidos. Corroboro que os teóricos do construtivismo acertam quando afirmam que os agentes do mundo são os construtores da própria história, mesmo que esta sofra as intempéries do tempo ou mesmo a ação da história, muitas vezes revelada pela literatura. Portanto, o mundo não nos é meramente imposto, predeterminado, mas sim passível de modificações, mutações e transformações, o que pode ocorrer dentro de certos limites, do acaso, das consequências das nossas próprias atitudes e decisões. Como eles mesmos dizem: "Em outras palavras, o mundo é socialmente construído". 
Portanto, o construtivismo reflete não apenas as teorias das Relações Internacionais, mas também dialoga com outras ciências sociais e humanas, facultando-nos, desta forma, os seguintes questionamentos: o que vem antes, os agentes ou a estrutura? Quem influencia, constrange ou limita as opções e a evolução do outro? Na literatura, podemos nos debruçar no Livro do Gênesis, da Bíblia cristã: o que existiu antes, o pecado ou o pecador? Isto nos dá panos para as mangas. E é justamente isto que a ciência nos faculta: pesquisar sempre, pois nada se responde nem se esgota de uma única vez. Quem faz a ciência, portanto, sempre busca algo novo, fere o tempo com novos conhecimentos e opiniões, embora sabendo que nada se esgota de todo. Então, o conhecimento que temos em relação ao mundo é socialmente construído, mas o mundo existe independentemente de tal conhecimento. Existe, pois, um continuum de posturas entre todos esses limites.

Nogueira e Messari (2005) finalizam:

No debate agentes-estrutura, os construtivistas negam simultaneamente que os agentes precedam a estrutura e a moldam para servir seus interesses e suas preferências, e que a estrutura tenha capacidade de constranger e limitar as opções e, portanto, as ações dos agentes. Para eles, agentes e estrutura são có-constitutivos uns dos outros, e nenhum precede o outro nem no tempo, nem na capacidade de influenciar o outro.

Concluindo, somos agentes ativos de um mundo que se transforma e conosco caminham os momentos históricos, como os lavrados na literatura por José do Patrocínio, seja na observação e registro literários da realidade observada nos estados nordestinos - mais precisamente em Viagem ao Norte - Apontamentos de José do Patrocínio -, seja na tese apresentada em Os Retirantes. Mediante tal material apresentado pelos autores das Relações Internacionais e as lições literárias, só nos resta uma escolha: agir num universo em constante ebulição, construindo, com escolhas conscientes, a própria história. 


\section{Referências}

CASTRO, Thales. Teoria das Relações Internacionais. Brasília: Fundação Alexandre de Gusmão, 2012.

JATOBÁ, Daniel. Teoria das Relações Internacionais. São Paulo: Saraiva, 2013.

MESSARI, Nizar; NOGUEIRA, João Pontes. Teoria das Relações Internacionais Correntes e Debates. Rio de Janeiro: Elsevier/Campus, 2005.

MEYER, Marlyse. Folhetim. São Paulo: Companhia das Letras, 2005.

MOISÉS, Massaud. A Criação Literária - Prosa II. São Paulo: Cultrix, 1979.

PATROCÍNIO, José. Os Retirantes. São Paulo: Editora Três, 1973.

SARFATI, Gilberto. Teorias de Relações Internacionais. São Paulo: Saraiva, 2005.

SIMÕES, Ricardo Japiassu. Viagem ao Norte - Apontamentos de José do Patrocínio. Recife: Editora Universitária da UFPE, 2015.

SODRÉ, Nelson Werneck. História da Imprensa no Brasil. Rio de Janeiro: Graal, 1977.

TUZINO, Yolanda Maria Muniz. Crônica: uma Interseção entre o Jornalismo e a Literatura, 2009. Disponível em: http://www.boc.ubi.pt/pag/tuzino-yolandauma-interpretação.pdf. 